\title{
Erratum: Phytochemical Screening and Gas Chromatography-Mass Spectrometry Analysis of Ethanol Extract of Scambiosa columbabria L.
}

In the article titled "Phytochemical Screening and Gas Chromatography-Mass Spectrometry Analysis of Ethanol Extract of Scambiosa columbabria L.", published on pages 35-39, Issue 1, Volume 12 in Pharmacognosy Research, ${ }^{[1]}$ the terms "Scabiosa columbaria L.", S. columbaria" and "Scabiosa columbaria" were misspelled as "Scambiosa columbabria L.", "S. columbabria" and "Scambiosa columbabria" respectively in the title as well as throughout the article including figures, tables, and legends. The term "insulin-mimicking activity" was misspelled as "insulin-mimickingactivity," on page $38,14^{\text {th }}$ line of paragraph RESULTS AND DISCUSSION.

The "How to cite this article" section should read correctly as "Sagbo IJ, Orock AE, Kola E, Otang-Mbeng W. Phytochemical screening and gas chromatography-mass spectrometry analysis of ethanol extract of Scabiosa columbaria L. Phcog Res 2020;12:35-9".

\section{REFERENCE}

1. Sagbo IJ, Orock AE, Kola E, Otang-Mbeng W. Phytochemical screening and gas chromatography-mass spectrometry analysis of ethanol extract of Scambiosa columbabria L. Phcog Res 2020;12:35-9.

DOI: $10.4103 / 0974-8490.284429$ 